\title{
Performance of Routing Schemes in Wireless Sensor Network
}

\author{
Poonam T. Agarkar', Manish D. Chawhan ${ }^{2}$, Pradeep T. Karule ${ }^{3}$ and Pratik R. Hajare ${ }^{4}$ \\ ${ }^{1} P h D$. Scholar, Electronics Engg., YCCE, Nagpur, Maharashtra, India \\ ${ }^{2}$ Associate Professor, ETC Department, YCCE, Nagpur, Maharashtra, India \\ ${ }^{3}$ Professor \& Head, Electronics Engg., YCCE, Nagpur, Maharashtra, India \\ ${ }^{4}$ Director, The Pearl Engineering Solutions, Nagpur, Maharashtra, India
}

\begin{abstract}
Adhoc on Demand Distance Vector (AODV) mechanism had been extensively incorporated with various scenario of Wireless Sensor networks to evaluate various performance parameters. The work presented in this paper is a comparative analysis between AODV and other two standard routing protocols named Destination Sequenced Distance Vector (DSDV) and Dynamic source routing (DSR) protocols. A scenario of 17 nodes is created using NS2 Scenario Generator/NetSim with some mobile nodes and Tool Command Language (TCL) file has been created using New trace file format to extract the required information for writing the AWK scripts for estimation of Packet Delivery Ratio (PDR), Throughput, End to End (E2E) Delay, Energy of the Network, Packets delivered by the sensor nodes and packet accepted by the final nodes. The result obtained showed that AODV have higher throughput, E2E delay and also the numbers of packet sent and received than DSDV and DSR. DSR have higher throughput than DSDV. The PDR is higher in case of DSR and DSR has higher throughput than DSDV while the residual network energy of AODV and DSDV is higher than DSR.
\end{abstract}

KEY WORDS: ADHOC ON DEMAND DISTANCE VECTOR (AODV), WIRELESS SENSOR NETWORKS, DESTINATION SEQUENCED DISTANCE VECTOR (DSDV), DYNAMIC SOURCE ROUTING (DSR), NS2 SCENARIO GENERATOR, TOOL COMMAND LANGUAGE, PACKET DELIVERY RATIO (PDR), END TO END (E2E) AND THROUGHPUT.

\section{INTRODUCTION}

Due to immense increase in wireless network users and availability of mobile devices, there was an explosion in wireless sensor applications over the last decade [Munisha Devi et. al., 2019, L. Guaya-Delgado et. al., 2019, Rutvij H. Jhaveri, et al., 2018, S.L. Meshram and P.D. Dorge. 2017]. Beside improved quality service and mobility, networks have enhanced organizations and corporates with respect

\section{ARTICLE INFORMATION}

*Corresponding Author: poonamagarkar71@gmail.com Received 17th Oct 2020 Accepted after revision 26th Dec 2020 Print ISSN: 0974-6455 Online ISSN: 2321-4007 CODEN: BBRCBA

Thomson Reuters ISI Web of Science Clarivate Analytics USA and Crossref Indexed Journal

\section{Clarivate Crossef}

NAAS Journal Score 2020 (4.31)

A Society of Science and Nature Publication,

Bhopal India 2020. All rights reserved.

Online Contents Available at: http//www.bbrc.in/

Doi: http://dx.doi.org/10.21786/bbrc/13.14/96 to their business and increased the productivity [A.M.E. Ejmaa et. al., 2015, Nguyen Dinh Han et. al., 2015, H. Xiao et. al., 2014 and C.R. Komala et. al., 2010]. The primary goal of a routing protocol $(\mathrm{Rp})$ in networks is to allow efficient flow of packets over the network. Rp's in wireless scenario has varied requirement as compared to wired network in terms of performance parameters. They are classified as proactive (PR) and reactive (RR) where the former only generate routes when data transmission is initiated. The AODV [E.M. Royer et. al., 2001 and B. Abasgholi et. al., 2008] is an example of RR and based on DSDV technique.

The mechanism of AODV is totally node dependent that is the current node decide where to route the packet in the network. A hop-by-hop transmission of packets is maintained by a route table consisting of three fields: hop count, sequence number and next hope node. Thus, individual packets find their own path and maintain their

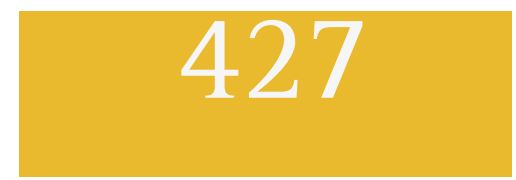


transmission link. Hello messages are delivered at regular intervals to nearby nodes. The three different messages used by AODV are Route Request (RREQ), Route Reply (RREP) and Route Error (RERR). For a packet in the network, the algorithm checks the route table to validate the connection. If the path is valid then the packet is transmitted to the next jumping node. It broadcast RREQ for route search, when it fails to do so. The format of the RREQ is shown in figure 1 below.

Figure 1: RREQ Packet in AODV

\begin{tabular}{|c|l|c|c|}
\hline Transmission ID & IP Address: Source & $\begin{array}{c}\text { Sequence Number: Destination } \\
\text { (Recent) }\end{array}$ & $\begin{array}{c}\text { Sequence Number: Source } \\
\text { (New) }\end{array}$ \\
\hline
\end{tabular}

Figure 2: WSN for 17 Nodes showing source and destination nodes.

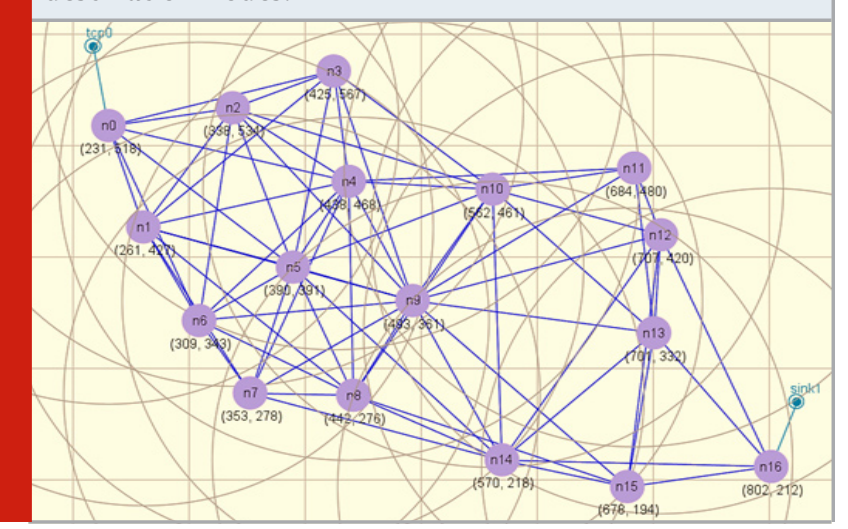

All the nodes receiving RREQ will update information as per the source and establish a reverse pointer to the sender in the routing table. The RREQ may be received by an intermediate node or the last node. The last or final node will send a RREP packet. This RREP packet will follow a reverse path via the intermediate nodes to the source and thus a link is established from the source to the end node. Once a path or route is maintained in the route table, any later RREQ to the destination is not forwarded but uses the same route in future. For any link failure or breakage within the network due to change in topology, information regarding invalid path is conveyed to all the nodes by itself. It is loop free, dynamic and multi-hop in nature. A WSN with 17 nodes generated in NS2 Scenario Generator/NetSim is shown in figure 2 below.

[Shaily Mittal and Prabhjot Kaur, 2009] varied pause time using random waypoint for their model and simulated the network for ' $\mathrm{N}=15$ ' times for CBR traffic. They considered ZRP (Zone Routing Protocol) instead of DSDV. They showed that average E2E delay of AODV was less, PDR to be high and hop count increased continuously with respect to other routing protocols. The effect of black hole attack on AODV and comparison with DSDV is listed in [A. A. Chavan et. al., 2016]. The author showed that PDR was reduced and throughput was zero with AODV considering the attack named black hole. Further they improved AODV and showed that both the parameters were unaffected at the cost of packet population. Anshuman Biswas et. al carried the simulations in NS2 using new trace format and compared AODV and DSR.
They analyzed the protocols by varying parameters such as network size, network load and mobility and made comparison in multiple dimensions. They showed that AODV performed better except for low mobility situations [Biswas A. et. al., 2012]. Similar work was carried out in [P. Manickam et. al., 2011] and the performance was analyzed using NS2 simulator with varying network size and simulation time. The author concluded that DSR was suitable for moderate traffic and mobility. DSDV produced low end to end delay as compared to others. PDR was better with AODV for low traffic. Another work carried by Thakre and Joshi in [Amit Thakre and Mrs. M. Joshi, 2010] using NS2 simulation showed that both Adhoc and Dynamic schemes are similar but AODV is easy to implement and use with other routing protocols and have good packet delivery ratio as compared to DSR whereas DSR is more stable and have low overheads.

Table 1 . Node movement initialized over the simulation time with respective speed.

\begin{tabular}{|l|l|l|l|l|l|l|}
\hline Node_I & X_init & Y_init & X_pos & Y_pos & Time & Speed \\
\hline 5 & 493 & 330 & 500 & 300 & 1 & 10 \\
\hline 5 & & & 600 & 500 & 10 & 30 \\
\hline 8 & 649 & 300 & 363 & 287 & 2 & 30 \\
\hline 8 & & & 695 & 54 & 8 & 25 \\
\hline
\end{tabular}

Table 2. Parameters initialized for AODV, DSDV and DSR Routing protocol for WSN.

\begin{tabular}{|l|l|l|}
\hline Sr. no. & Parameter & Value \\
\hline 1. & Routing Protocol & AODV/DSDV/DSR \\
\hline 2. & No. of Nodes & 17 \\
\hline 3. & X-Dimension & 1036 \\
\hline 4. & Y-Dimension & 646 \\
\hline 5. & Simulation Time & $25 / 1000 / 25$ \\
\hline 6. & Node Energy & 1000 \\
\hline 6. a. & Tx power & 0.9 \\
\hline 6. b. & Rx power & 0.4 \\
\hline $6 . c$. & Idle power & 0.05 \\
\hline $6 . d$. & Sleep power & 0.005 \\
\hline
\end{tabular}




\section{METHODOLOGY}

The simulation of the wireless sensor network was modelled using NS2 Scenario Generator/NetSim with 17 nodes placed over the default space region of 1036x646. Except two nodes with node ID's 5 and 8 all other nodes were assumed to be stationary without any movement over the complete simulation time whereas node 5 and 8 were free to move in the space as listed in the first table below. The values in the table are the node initial and final positions in the space and the time and speed at which they tend to move. The time indicates when the node will start moving in the space towards its new position as indicated by X_pos and Y_pos in the twodimensional space.

The various parameters initialized for the networks are listed below in table 2. Note that the simulation time for DSDV was increased to 1000 since for low simulation time, the packets transmitted were zero. The common parameters initialized for all three routing protocols are listed in table 3. The only change required for DSR routing is the type of QUEUE used. In case of AODV and DSDV, DropTail Priority queue is used whereas for DSR, CMUPriQueue is used instead of DropTail/PriQueue.

Table 3. Common parameters for routing protocols in WSN.

\begin{tabular}{|l|l|}
\hline Parameters & Description \\
\hline Channel & Wireless Channel \\
\hline Propagation & Two Ray Ground \\
\hline Network Interface Type & Wireless Phy \\
\hline MAC Type & 802 11 \\
\hline Interface Queue type & $\begin{array}{l}\text { DropTail/PriQueue for AODV and DSDV/ } \\
\text { CMUPriQueue for DSR }\end{array}$ \\
\hline Link Layer Type & LL \\
\hline Antenna Model & Omni Antenna \\
\hline Maximum Packet in IFQ & 50 \\
\hline
\end{tabular}

The instructions included in TCL file for defining New Trace File format, initializing interface Queue type for DSR routing and node energy initialization are listed below in figure 3: AWK (Aho, Weinberger and Kernighan, 1977) scripts were individually written for all the three routing protocols for the same 17 nodes wireless sensor network and results were evaluated for PDR, Throughput, E2E Delay and network residual Energy.

\section{RESULTS AND DISCUSSION}

The aim of the work was to compare the performance of three standard routing protocols with stationary and mobile nodes. Wireless Sensor Network with 17 nodes was simulated using NS2 Scenario Generator/ NetSim. Using New trace file format and AWK scripts the performance parameters PDR, Throughput, E2E-Delay and network residual Energy were estimated which are shown below in table 4 .

The results in table 4 clearly shows that the packet delivery ratio of DSDV is lower than other protocols where DSR has the highest value. Even at the initialization 429
Figure 3: TCL instructions for initialization.

11 For generating trace files with new format

Sns use new-trace

1) DSR protocol uses CMUPriQueue instead of DropTail/PriQueue if $\left\{\right.$ Sval(rp) $="$ "DSR" $\left.^{\prime}\right\}\{$

set val(ifq) CMUPriQueue

\} else \{

set val(ifq) Queue/DropTail/PriQueue \}

IFor Node Energy initialization

Sns node-config -energyModel "EnergyModel" \ -initialEnergy 1000.01

-txPower $0.9 \backslash$

-rxPower 0.4

-idlePower 0.05 ।

-sleepPower 0.005

Table 4. Estimated parameters for AODV, DSDV and DSR routing techniques in WSN.

\begin{tabular}{|l|l|l|l|}
\hline Estimated Parameters & AODV & DSDV & DSR \\
\hline PDR & 0.9611 & 0.2857 & 0.9774 \\
\hline Throughput (Kbps) & 213.65 & 0.0446 & 184.16 \\
\hline E2E Delay (milli second) & 33.496 & 0 & 26.47 \\
\hline Network Energy (Joules) & 5957.07 & 5694.31 & 5957.44 \\
\hline Packets Sent & 669 & 7 & 576 \\
\hline Packets Received & 643 & 2 & 563 \\
\hline
\end{tabular}

the simulation time for DSDV was increased to 1000 as compared to 25 for other two schemes to obtain some transmission of packets. The throughput and number of packets transmitted/received is higher in case of AODV. Both the parameters are considerably low for DSDV routing protocol for the same network. The overall residual energy of the network in DSR is slightly higher than AODV, where DSDV have the lowest value. The DSDV routing has superior performance in terms of E2E delay which is zero where AODV requires the maximum time.

\section{CONCLUSION}

It is seen from various literatures that there is no generalized routing scheme which can be suited for diverse applications to produce optimum results in terms of performance parameters. The objective is to have a generalized routing scheme meant for sensor networks which would yield the performance irrespective of the scenario and applications. One way is to combine the features of all the three routing schemes and incorporate some optimizing algorithms to design a better routing technique suitable for WSN. Some of the computational Intelligence based routing schemes are proposed in [Tarunpreet Kaur and Dilip Kumar, 2019] which includes fuzzy logic, reinforcement learning, particle swarm optimization, ant colony optimization, genetic algorithm, artificial bee colony optimization etc. 


\section{ACKNOWLEDGEMENTS}

This paper is the part of DST-SERB funded project titled "Energy and Communication Efficient Protocol of Mobile Adhoc Network using Cross Layer Approach", Grant Number: EEQ/2018/000542.

Declaration of interest: The authors report no conflicts of interest. The authors alone are responsible for the content and writing of this article.

\section{REFERENCES}

A.M.E. Ejmaa, S. Subramaniam, Z.A. Zukarnain, Z.M. Hanapi. (2016). Neighbour-based dynamic connectivity factor routing protocol for mobile ad hoc network. IEEE Access vol. 4, pp. 8053-8064.

B. Abasgholi, R. Kazemi, M. Arezoomand, A.R. Enayati (2008). Neighbour detection power control (NDPC) mac protocol in mobile ad hoc networks. 3rd International Symposium on Wireless Pervasive Computing. IEEE, pp. 508-512.

Biswas A., Saha B., Guha S. (2012). Performance Analysis of AODV and DSR Routing Protocols for Ad-Hoc Networks. Berlin, Heidelberg. In: Thilagam P.S., Pais A.R., Chandrasekaran K., Balakrishnan N. (eds) Advanced Computing, Networking and Security. ADCONS 2011. Lecture Notes in Computer Science, Springer, vol. 7135, pp. 297-305.

C.R. Komala, P.S. Srinivas Shetty, E. Elevarasi. (2010). Wireless ad hoc mobile networks. National Conference on Computing, Communication and Technology, pp. 168-174.

Chavan A. A. et. al. (2016). Performance Analysis of AODV and DSDV Routing Protocol in MANET and Modifications in AODV against Black Hole Attack. 7th International Conference on Communication, Computing and Virtualization, Elsevier, vol. 79, pp. 835-844.

Devi M. and Gill N. S. (2019). Mobile ad hoc networks and routing protocols in IOT enabled smart environment, a review. J. Eng. Appl. Sci. vol. 14, pp. 802-811.

E.M. Royer, P.M. Melliar-Smith, L.E. Moser. (2001).
An analysis of the optimum node density for ad hoc mobile networks. 3rd International Conference on Communications, IEEE, pp. 857-861.

H. Xiao, D.M. Ibrahim, B. Christianson. (2014). Energy consumption in mobile ad hoc networks. Istanbul: IEEE Wireless Communications and Networking Conference (WCNC), pp. 2599-2604.

Jhaveri Rutvij H. et al. (2018). Sensitivity analysis of an attack-pattern discovery based trusted routing scheme for mobile ad-hoc networks in industrial IOT. IEEE Access vol. 6, pp. 20085-20103.

Kaur T. and Kumar D. (2019). Computational intelligence-based energy efficient routing protocols with QoS assurance for wireless sensor networks: a survey. Int. J. Wireless and Mobile Computing, vol. 16, No. 2, pp. 172-193.

L. Guaya-Delgado, E. Pallarès-Segarra, A.M. Mezher, et al. (2019). A novel dynamic reputation-based source routing protocol for mobile ad hoc networks. J. Wireless Com. Network, article no. 77, pages -16 .

Meshram S.L. and Dorge P.D. (2017). Design and performance analysis of mobile ad hoc network with reactive routing protocols. Chennai: International Conference on Communication and Signal Processing (ICCSP), IEEE, pp. 0443-0447. Mittal S. and Kaur P. (2009). Performance comparison of aodv, dsr and zrp routing protocols in MANET's. Trivandrum, Kerela: International Conference on Advances in Computing, Control, and Telecommunication Technologies, IEEE, pp. 165-168.

Nguyen Dinh Han, Yonghwa Chung, Minho Jo. (2015). Green data centres for cloud assisted mobile ad hoc networks in 5G. IEEE Networks, vol. 29, pp. 70-76.

P. Manickam et. al. (February 2011). Performance comparisons of routing protocols in mobile ad hoc networks. International Journal of Wireless \& Mobile Networks (IJWMN), vol. 3, no. 1, pp. 98-106.

Thakre A. and Mrs. Joshi M. (2010). Performance Analysis of AODV \& DSR Routing Protocol in Mobile Ad hoc Networks. IJCA Special Issue on "Mobile Ad-hoc Networks” MANETs, vol. 4, pp. 211-218. 